\title{
Amniotic Fluid Leak
}

National Cancer Institute

\section{Source}

National Cancer Institute. Amniotic Fluid Leak. NCI Thesaurus. Code C92824.

The discharge of amniotic fluid vaginally due to a tear or rupture in the amniotic membrane. 